\section{Genetic Methods for Mitigating Invasiveness of Woody Ornamental Plants: Research Needs and Opportunities}

\author{
Kelly J. Vining \\ Department of Forest Ecosystems and Society, Oregon State University, 338 \\ Richardson Hall, Corvallis, OR 97331-5752
}

\author{
Ryan N. Contreras \\ Department of Horticulture, Oregon State University Corvallis, OR 97331- \\ 7304
}

\author{
Martin Ranik and Steven H. Strauss ${ }^{1}$ \\ Department of Forest Ecosystems and Society, Oregon State University, 338 \\ Richardson Hall, Corvallis, OR 97331-5752
}

Additional index words. containment, sterility, hybridization, polyploidy, mutagenesis, genetic engineering

\begin{abstract}
Because cultivation of exotic woody ornamental plants has led to establishment of a number of invasive species, there is considerable interest in breeding methods to reduce the propensity for spread. We review progress in conventional breeding and transgenic biotechnology approaches to producing sterile forms of ornamental woody plants. Conventional forms of inducing sterility, including induction of polyploidy, interspecific hybridization, and mutagenesis, are generally inexpensive and can be applied to a diversity of species at low to moderate cost. They have also been shown to be capable of producing commercially successful cultivars. In contrast, despite a variety of highly promising and rapidly developing approaches using transgenic methods, the inability to efficiently regenerate and genetically transform most ornamental species makes application of these innovations highly problematic. Moreover, because of the fragmented pattern of ornamental nursery ownership, the numerous species and varieties used, and the high regulatory cost for permits to sell most types of transgenic varieties (even when their environmental risk of spread has been reduced by sterility), application of transgenic methods is largely infeasible. A combination of fundamental regulatory reform and expanded biological research on generalized transformation and sterility methods is needed to overcome these barriers.
\end{abstract}

As a result of intentional and unintentional movement of seeds and other propagules around the world, a large number of exotic species have established self-sustaining populations. Exotic woody ornamentals are widely

Received for publication 24 Apr. 2012. Accepted for publication 26 June 2012.

We thank the following programs for support of this work: USDA-ARS-Invasive Species, Project Title: Mechanisms for creating non-invasive nursery crops. Project No. 1230-21000-051-06S; USDA-BRAG, Project Title: Genetic containment of plants using zinc-finger nucleases. Project No. 2010-33522-21736; USDA-AFRI-CAP, Project Title: System for Advanced Biofuels Production from Woody Biomass in the Pacific Northwest. Project No. 2011-68005-30407; and Tree Biosafety and Genetics Research Cooperative (TBGRC) Members: Futuragene (Israel), Arborgen, LLC (South Carolina, U.S.A.), Sappi (South Africa), and SweTree Technologies AB (Sweden). We thank Tom Ranney and Margaret Pooler for comments on an earlier version of this manuscript.

${ }^{1}$ To whom reprint requests should be addressed; e-mailsteve.strauss@oregonstate.edu. introduction does or is likely to cause economic or environmental harm or harm to human health" (Clinton, 1999).

The numerous exotic species that have been established may have negative or positive ecological effects. Richardson and Pyšek (2006) described the use of exotic species in habitat restoration on sites where native species may not survive or fully occupy or do not provide as full a range of ecosystem services. More than 4000 non-native species are considered naturalized to some degree in North America; however, there do not appear to be any native species that have gone extinct as a result of competition from these introduced species (Dehnen-Schmutz, 2011). Thus, considering plant species presence alone, there has been a large net increase in plant diversity in some ecosystems as a result of introduction of exotics. Moreover, because many have unique ecophysiological characteristics, the adaptive resilience of the ecosystems they have occupied is likely to have been increased in many cases. Nonetheless, it is also clear that many exotic invasive species have had large unintended ecological impacts such as driving native species to reduced frequency as a result of their dominance and thus substantially affecting ecosystem structure, trophic relationships, hydrology, and biogeochemistry (Gordon, 1998; reviewed in Li et al., 2004). Thus, measures to avoid or reduce unintended ecological impacts are needed.

As a precautionary measure, especially in cases in which a species to be introduced has characteristics known to promote invasiveness, or has relatives already identified as invasive (Reichard and Hamilton, 1997), it is highly desirable to reduce the potential for invasiveness as part of ornamental breeding programs. Prevention of invasiveness by cultural means is often sought too late; once spread has been extensive, eradication is often impossible, extremely expensive, and damaging to ecosystems. The economic impact of a subset of invasive plant species, including losses and costs of control, has been estimated to be nearly $\$ 35$ billion (Pimentel et al., 2005). Thus, strong investments in prevention of invasiveness during plant breeding seem well justified.

The goal of this article is to review the different means by which the potential for invasiveness can be reduced using genetic methods. We focus on the reduction of sexual fertility; however, because many invasive species also spread by vegetative means, efforts directed at prevention of vegetative spread such as by reduced rootability or tillering could also be achieved if they do not also prevent variety propagation. However, we know of no cases in which work toward reducing the capacity for vegetative spread as a means of risk reduction has been carried out. Because significant reductions in the number of exotic propagules reduce the risk of invasion substantially (Richardson and Pyšek, 2006), we consider that large reductions in fertility will be biologically significant, even if imperfect. However, we expect that achieving complete sterility will 
be feasible in many cases given sufficient chromosomal disturbance or directed mutagenesis, as discussed below.

We consider both traditional and genetic engineering (GE), or "transgenic," approaches to breeding for reduced fertility. Conventional forms include interspecific hybridization, polyploidization, and non-specific mutagenesis, all of which have led to commercialized varieties. GE is supported by rapidly expanding science and technology but, to our knowledge, has not led to any commercial releases for woody ornamental plants. We will consider the technical approaches and limitations of both approaches as well as the social issues that are a significant obstacle for GE approaches. We emphasize results with angiosperms; however, progress in gymnosperms shows that the same methods - both conventional (Contreras et al., 2010) and GE (Strauss et al., 2011) - are applicable to them. This review builds on and updates the science and technology presented in earlier reviews, including those by Brunner et al. (1998, 2007), Li et al. (2004), Skinner et al. (2000), and Strauss et al. (1995).

\section{Conventional Options for Sterility Breeding}

Induced polyploidy. Induced polyploidy is a widely used technique in plant breeding. Typically, meristems are treated with antimitotic agents such as colchicine or dinitroaniline herbicides such as oryzalin or trifluralin. Blakeslee and Avery (1937) described numerous techniques to apply colchicine to various taxa including soaking seeds, immersion of shoot tips, covering shoot tips with agar or lanolin solutions, spraying an atomized solution, and the single drop method. These techniques, and modifications thereof, have been used to apply colchicine and oryzalin to woody horticultural crops to develop polyploids. These techniques require little equipment, are not technically challenging, require no genomic information, and in most cases can be done in a short amount of time. Labor costs are generally low as a result of the short duration of treatment, and materials involved are low-cost items such as growing supplies, agar, and oryzalin or colchicine. As a result, developing polypoids through traditional in vivo means is inexpensive. In contrast, in vitro chromosome doubling — also commonly using colchicine and oryzalin-is labor-intensive and requires more technical expertise and equipment, which makes it more costly.

Often, the greatest expense of either traditional or in vitro polyploidization is screening for polyploids. In some cases, phenotypic markers are useful in selecting for potential chromosome-doubled plants. Induced polyploidy can sometimes lead to "gigas" effects that result in larger organs than in the diploid, particularly in determinate organs such as flowers, fruits, and seeds (Stebbins, 1950). However, the effects of polyploidy on the size of individual organs as well as overall plant size and vigor is inconsistent (Randolph, 1941). In japanese-cedar [Cryptomeria japonica (L.f.)
D. Don], Contreras et al. (2010) selected seedlings that had thick and twisted needles, a phenotype that proved to be over $92 \%$ accurate in predicting polyploidy, thus reducing screening costs. However, diploids and tetraploids of Platycladus orientalis (L.f.) Franco (syn = Thuja orientalis L. f.), Thuja plicata D. Don., and T. occidentalis L. show no discernible morphological differences; therefore, all treated seedlings must be screened (R. Contreras, unpublished data).

Induced polyploidy has been used in a wide array of economically important woody ornamental taxa, indicating that the technique is widely applicable. Angiosperm families with induced polyploids include the Theaceae (Ackerman and Dermen, 1972), Rosaceae (Kermani et al., 2003), Ericaceae (Contreras et al., 2007; Jones et al., 2008; Kehr, 1996), Bignoniaceae (Olsen et al., 2006a), Malvaceae (Contreras et al., 2009; Egolf, 1970), Hypericaceae (Olsen et al., 2006b), Oleaceae (Rose et al., 2000a), and Buddlejaceae (Dunn and Lindstrom, 2007; Rose et al., 2000b). Most of the polyploids developed in these families have not been dominant in the market; however, the roseof-sharon (Hibiscus syriacus L.) cultivars developed by Egolf, including 'Aphrodite', 'Diana', 'Helene', and 'Minerva' (Egolf, 1970, 1981, 1986, 1988), remain popular selections.

Induced polyploidy has been applied to a number of invasive or potentially invasive species and to genera in which one or more species have been identified as weedy or invasive. Pyrus L. has been treated in vitro using colchicine to produce triploid, mixoploid $(2 x+4 x)$, and tetraploid explants (Kadota and Niimi, 2002; Sun et al., 2009). Lehrer et al. (2008) treated meristematically active seeds of Berberis L. (barberry) with oryzalin to develop tetraploids. Rounsaville and Ranney (2010) confirmed induced polyploids of barberry were tetraploid; however, the method of polyploidization was not indicated for the plants studied. In Lonicera L. there has been successful development of polyploids by in vivo (Li et al., 2009a) and in vitro (Suzuki et al., 2006) treatment with colchicine. Dunn and Lindstrom (2007) reported induced polyploids of Buddleja L. after in vitro treatment with oryzalin. Rose et al. (2000b) recovered tetraploids after in vitro treatment with colchicine.

Induced polyploids, often tetraploids, may be backcrossed to untreated diploid genotypes to produce progeny with odd ploidy levels, often triploid. Triploid progeny generally exhibit reduced fertility, sometimes approaching complete sterility. However, compared with the number of woody ornamental taxa for which there are induced polyploids, there are relatively few documented cases in which an induced polyploid was subsequently backcrossed to produce triploids. Egolf developed a tetraploid form of the rose-of-sharon cultivar, William R. Smith, that he backcrossed to diploids to develop the triploid cultivars Diana (Egolf, 1970), Helene (Egolf, 1981), Minerva (Egolf, 1986), and Aphrodite (Egolf, 1988). The weedy species Hypericum androsaemum L. was treated with oryzalin in vivo (Olsen et al., 2006b) and in vitro (Meyer et al., 2009b) to develop tetraploids. Olsen et al. (2006b) backcrossed tetraploids to diploids to develop a triploid series that in preliminary tests were sterile; Trueblood et al. (2010) confirmed these results.

In addition to in vivo and in vitro treatments of meristems to develop polyploids, several groups have begun taking advantage of the naturally occurring polyploidy in endosperm. Direct culture of endosperm may eliminate the need for chromosome doubling and subsequent backcrossing. Thammina et al. (2011) used endosperm as explants to culture burning bush [Euonymus alatus (Thunb.) Sieb.] and recovered eight triploid plants. Also, Miyashita et al. (2009) successfully regenerated plants from endosperm of self-pollinated tetraploid $(2 n=4 x=36)$ lines of Lonicera caerulea var. emphyllocalyx Nakai and confirmed that plantlets maintained the same ploidy level as endosperm $(2 n=6 x=54)$. We are not aware of data for either case on the relative fertility of the resulting plants.

Interspecific hybridization. Aside from selection and open pollination, the most common technique used in breeding of woody ornamental cultivars appears to be interspecific hybridization. The resulting hybrids are often sterile as a result of structural differences in parental chromosomes, which result in improper chromosome pairing during gametogenesis. Sterility resulting from meiotic abnormalities is often referred to as hybrid sterility or chromosomal hybrid sterility and represents an opportunity for breeders to develop new cultivars that exhibit novel phenotypes and also have a reduced risk of escaping cultivation. Instances of sterile hybrids are numerous in genera of woody ornamental plants, including Camellia L. (Ackerman and Dermen, 1972), Bougainvillea Comm. ex Juss. (Zadoo et al., 1975), Rosa L. (Kermani et al., 2003), Rhododendron L. (Contreras et al., 2007), and Lagerstroemia L. (Pounders et al., 2007).

Interspecific hybridization has also been applied in genera that have been reported to be invasive. Interspecific hybrids were developed between species of Buddleja to develop 'Blue Chip' (Werner and Snelling, 2009) and 'Asian Moon' (Renfro et al., 2007), both of which are reported to produce few to no viable seeds. Van Laere et al. (2009) reported that $\mathrm{F}_{1}$ progeny of Buddleia davidii Franch. $\times$ $B$. lindleyana Fort. ex Lindl. were almost sterile and were not able to produce an $\mathrm{F}_{2}$ generation. One risk of this approach, however, is that interspecific hybridization can also increase invasive potential through, among other factors, generation of novel genotypes and increased genetic variation (Ellstrand and Schierenbeck, 2000). Thus, an extremely high level of sterility, and preferably complete sterility, is highly desirable in hybrids involving known invasive species.

Mutagenesis. Sterility is one of the most common effects of mutagenic treatment (Lapins, 1983). We know of few published reports of cultivar development of woody ornamental plants using mutagenesis; most 
information on the effects of chemical and physical mutagens on fertility comes from research done on woody fruit trees. Lapins (1975) observed reduced male and female fertility in diploid mutants of apricot (Prunus armeniaca L.) after treatment with colchicine. Seedless berries of grape were recovered after treatment of dormant buds with X-rays (Olmo, 1960). Similarly, after exposure of scion wood of lemon to gamma radiation, seedless fruit were observed (Gulsen et al., 2007). Compared with the ploidy changes in hybridization, this method allows sterile forms of a valued variety to be largely retained while imparting sterility. The efficiency of this method compared with ploidy changes and hybridization is unknown; however, this method does require careful calibration of mutagen levels if the goal is to preserve phenotypic and chromosomal integrity while producing sterile forms.

\section{Genetic Engineering Options for Sterility Breeding}

GE involves the direct, asexual modification of cells and their regeneration into non-chimeric, differentiated plants. These approaches do not require that DNA from distant organisms be used; in fact, there is increasing interest in using "cisgenic" or "intragenic" approaches, for example to transfer genes for disease resistance, flowering, fruit quality, stature, or growth rate (Viswanath and Strauss, 2010). There is also increasing interest in directed mutagenesis, in which little or no transgenic DNA is permanently inserted for induced sterility and other goals (Wang et al., 2011a). However, for all GE methods, it is essential to be able to insert DNA into cells, select the modified cells from a large population of unmodified cells, and then regenerate those cells into healthy, differentiated plants, a process generally referred to as "transformation." Unfortunately, for the large variety of ornamental woody plants, transformation is very difficult to do, and for many taxa, it has never been accomplished. We therefore briefly review the transformability of ornamental woody plants before considering methods for engineering sterility.

Transformability of ornamental woody plants. Currently, few woody species can be regenerated or transformed. Of the representative, north temperate invasive woody genera listed in Table 1, cellular regeneration systems suitable for transformation through organogenic or embryogenic pathways, or actual evidence of production of transgenic plants, has been observed in only three genera in the order Rosales: apple (Malus Mill.), pear (Pyrus), and elm (Ulmus) (Gartland et al., 2000; Newhouse et al., 2006). However, only for Malus has there been extensive research on regeneration/transformation systems (Bhatti and Jha, 2010; Flachowsky et al., 2009; Tränkner et al., 2010; Yamagishi et al., 2010; Zhu et al., 2007), and none of these efforts aim to decrease sexual fertility. The lack of research in the other genera likely reflects both limited commercial interest in intensive breeding in general and low interest in sterility breeding in particular. However, it is also likely that the taxa are inherently recalcitrant to transformation, as are most woody taxa (Schuerman and Dandekar, 1993). In addition to the usual empirical studies to improve regenerability and transformation such as screening of genotypes, culture media, hormones, and environmental conditions, these genera might benefit from the use of newly identified gene transfer and regeneration-promoting genes that directly affect DNA uptake and cellular competence for differentiation (Arias et al., 2006; Gelvin, 2003; Wang et al., 2011b). However, we are aware of no published studies of the value of such genes for recalcitrant woody plants.

Genetic engineering strategies for sterility. A variety of molecular approaches to species or transgene containment have been developed in model species (reviewed in Brunner et al., 2007). One is ablation, in which a cytotoxic protein such as RNAse, driven by a floral specific promoter, destroys or severely disturbs floral tissue development (Fig. 1). A second approach is gene overexpression or suppression, the latter often using RNA interference (RNAi) or introduction of dominant negative mutant forms of target proteins to suppress the function of genes essential for fertility. The expression changes can lead to abnormal, non-fertile organs or prevention of flowering onset entirely. Gene suppression can also be obtained through epigenetic mechanisms such as DNA methylation (Liu and Li, 2011). A third tactic is directed mutagenesis of genes required for fertility using zinc finger or TALEN nucleases (Bogdanove and Voytas, 2011); a related method uses excision/recombinase technologies, in which site-specific recombinases remove transgenes and prevent gametic transmission (Wang et al., 2011a). This method, however, would not contribute toward containment of an invasive variety.

Ablation is the original transgenic method for inducing sterility, demonstrated to be successful for both male and female sterility in tobacco (Nicotiana tabacum L.) and in Brassica L. species (Goldman et al., 1994; Mariani et al., 1990). It has also been demonstrated to be highly effective for male sterility in the field in a number of woody tree species, including Populus L., Pinus L., and Eucalyptus L'Hér. (Strauss et al., 2011; Zhang et al., 2012). In these studies, a single tapetal-dominant promoter and RNAse were used-obviating the need for taxon-specific

Table 1. Genomic and model plant resources, and amenability to transformation, for invasive ornamental taxa. ${ }^{z}$

\begin{tabular}{|c|c|c|c|c|c|c|}
\hline Order & Family & Genus & $\begin{array}{l}\text { Regeneration, } \\
\text { transformation }^{\mathrm{y}}\end{array}$ & $\begin{array}{l}\text { Nucleotide sequence } \\
\text { records in Genbank }\end{array}$ & Closest model genome & $\begin{array}{l}\text { Model genome database } \\
\text { resource }\end{array}$ \\
\hline Sapindales & Sapindaceae & Acer & - & 3516 & Arabidopsis thaliana $^{\mathrm{x}}$ & Phytozome \\
\hline Rosales & Rosaceae & Malus & ++ & 6037 & Malus $\times$ domestica ${ }^{\mathrm{w}}$ & GDR \\
\hline Rosales & Rosaceae & Crataegus & - & 1139 & Malus $\times$ domestica ${ }^{\mathrm{w}}$ & GDR \\
\hline Rosales & Rosaceae & Spiraea & - & 209 & 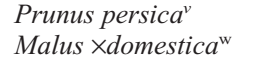 & GDR \\
\hline Rosales & Rosaceae & Pyrus & + & 2201 & Malus $\times$ domestica $^{\mathrm{w}}$ & GDR \\
\hline Rosales & Ulmaceae & Ulmus & + & 121 & Malus $\times$ domestica $^{\mathrm{w}}$ & GDR \\
\hline Lamiales & Oleaceae & Ligustrum & - & 537 & Antirrhinum majus & N/A \\
\hline Dipsacales & Caprifoliaceae & Lonicera & - & 1098 & Helianthus annuus & $\mathrm{N} / \mathrm{A}$ \\
\hline Celastrales & Celastraceae & Euonymus & - & 418 & Populus trichocarpa $^{\mathrm{u}}$ & Phytozome \\
\hline Ranunculales & Berberidaceae & Nandina & - & 48 & Papaver & N/A \\
\hline Ranunculales & Berberidaceae & Berberis & - & 859 & Papaver & N/A \\
\hline Aquifoliales & Aquifoliaceae & Ilex & - & 1667 & Helianthus annuus & N/A \\
\hline Lamiales & Scrophulariaceae & Buddleja & - & 80 & Antirrhinum majus & N/A \\
\hline
\end{tabular}

${ }^{\mathrm{z}}$ Taxa were included based on economic importance to the nursery industry and relative invasive potential as indicated by their presence on state or regional noxious weed and/or watch lists compiled by government (e.g., United States Department of Agriculture, 2012) and non-government (e.g., University of Georgia, 2012) organizations.

${ }^{\mathrm{y} B a s e d}$ on searches on literature in EBSCO Host databases for agricultural science from 2000 through 2011. A “_" means an apparent absence of publications showing cellular regeneration or transformation of transgenic plants, “+” means a small number (less than 10), "++" means a large number (greater than 10). ${ }^{x}$ The Arabidopsis Genome Initiative, 2000.

"Velasco et al., 2010.

vosinski et al., 2010.

"Tuskan et al., 2006.

GDR = Genome Database for the Rosaceae.

$\mathrm{N} / \mathrm{A}=$ not applicable. 


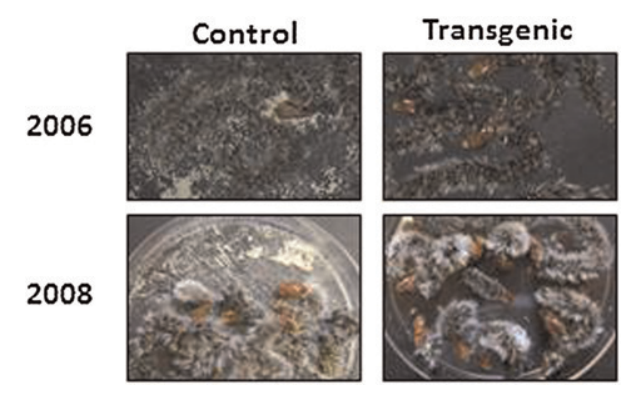

Fig. 1. High level of male sterility attained in a Populus tremula $\times$ alba hybrid through transformation with tapetal-specific promoter TA29 driving the ribonuclease barnase. Results from 2006 were reported in Brunner et al. (2007). Mature catkins from field-grown trees were allowed to dehisce, then pollen was forcibly discharged in petri dishes in the laboratory. One representative transgenic event lacking visible pollen is shown.

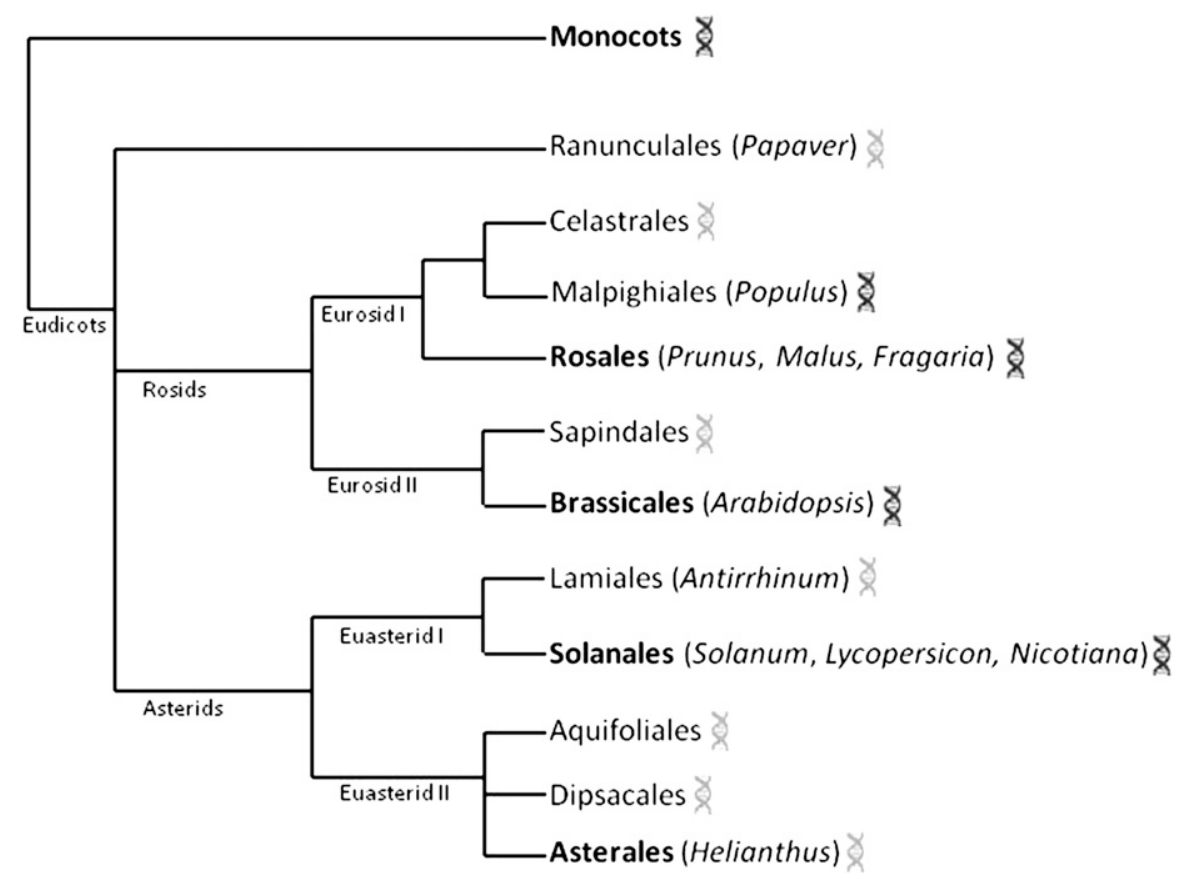

Fig. 2. Phylogeny of invasive woody plants and potential model genera. Orders of woody dicotyledonous plants are represented in a phylogeny together with potential genetic models (bold). Orders containing species with fully sequenced genomes are highlighted with a black DNA icon, whereas orders that contain species for which a transcriptome has been sequenced are marked with a gray DNA icon.

transgenic constructs that the other methods discussed usually require.

The RNAi approach has been used in numerous model and woody plant species, both to influence fertility and flowering onset. For example, RNAi suppression of the centromeric nucleosome protein $\mathrm{CENH} 3$ postponed flowering in Arabidopsis Heynh. (Lermontova et al., 2011). RNAi suppression of $L E A F Y$ from Populus led to sterility in tobacco, showing that RNAi can in some cases be effective across plant families (An et al., 2010). RNAi suppression of homologs to the meristem identity genes CENTRORADIALIS/ TERMINAL FLOWER 1, key regulators of floral onset and inflorescence structure, resulted in the opposite effect, giving precocious flowering in Malus and Populus (Mohamed et al., 2010; Szankowski et al., 2009). Dominant negative forms of floral transcription factors, induced using the EAR protein motif, led to high levels of sterility in Arabidopsis (Hiratsu et al., 2003).

An alternative, and theoretically superior form of floral gene suppression, involves mutation of genes essential for reproduction using site-specific nucleases. If efficient enough to mutate both alleles in heterozygous, outbreeding woody ornamental plants, this should result in a highly stable and highly predictable form of sterility. Zinc finger nucleases have been mostly widely used for this purpose and appear to mutate target genes at high efficiency (Curtin et al., 2011; Shukla et al., 2009; Zhang and Voytas, 2011). TALEN nucleases, based on naturally occurring plant pathogen effector proteins, appear to also be highly efficient and simpler than zinc finger nucleases in targeting sequence design (Bogdanove and Voytas, 2011). How- ever, we know of no cases in which nuclease technology has been applied to woody plants.

Instead of inducing sterility, transgenes can be excised from the genome before normal gamete development using site-specific recombinases driven by gametogenesis-specific promoters (Moon et al., 2011). Site-specific recombinases are a group of enzymes that precisely cut and then ligate DNA without nucleotide gain or loss. These enzymes recognize recombination sites that flank transgene cassettes and, if the target repeat sites are in direct orientation, can excise the transgene therein. The site-specific recombination approach was among the first used to generate transgenic plants free of a selectable marker and included phage Cre-lox and yeast FLP$F R T$ and R-RS systems (Moon et al., 2011). In tobacco, highly efficient transgene excision in pollen was achieved using the unidirectional serine recombinase $\mathrm{CinH}-\mathrm{RS} 2$ driven by a pollen-specific promoter. However, we know of no published applications in woody plants.

Woody plants, particularly long-lived species like forest trees, remain non-reproductive for many years before onset of flowering. This may involve the juvenile expression of repressors, perhaps associated with epigenetic modifications (Brunner and Nilsson, 2004). In model plant species, floral repressors such as the MADS-box transcription factor FLOWERING LOCUS C (FLC) (Michaels and Amasino, 1999) have been identified and might be used to delay flowering by their overexpression. If woody plants can be maintained in a pre-reproductive state indefinitely, this might be the most reliable form of sterility. Of course, where the flowering/fruits of woody ornamentals are important, this method would not be applicable. Again, we know of no cases in which this has been demonstrated in woody plants.

Similarly, overexpression of miRNAs that are capable of preventing the onset of flowering is also an attractive option. However, they often have pleiotropic effects such as dwarfing and modification of expression of several other transcription factors seen with ectopic expression of corngrass 1 (Chuck et al., 2011), and the substantial morphological variation seen in poplar overexpressing the juvenility-associated miR156 (Wang et al., 2011b).

Genomic resources to support genetic engineering and marker breeding. Molecular biotechnologies, whether transgenic or based on DNA markers and sequencing, begin with knowledge of gene sequences and their variation, expression, and ultimately functional and phenotypic consequences. Although this information is best obtained in model species - for which the phylogenetic proximity to ornamental plants of interest is beneficial if not essential (Fig. 2) - its ultimate application usually requires study and testing in the target ornamental taxa. This is because flowering pathways vary substantially over taxa, and marker and transgenic methods usually require that the sequence and expression of the target genes or promoters are known. Fortunately, as 
a result of DNA sequencing innovations, obtaining gene sequence and expression information on a large scale in non-model species has never been easier or less costly.

The arrival of several massively parallel, inexpensive sequencing technologies has changed the applicability of sequencing to basic and applied biology (Martinez and Nelson, 2010; Shendure and Ji, 2008). In addition to DNA, sequencing can be applied to RNA, enabling study of genome-wide expression in organisms with few other genomic resources (Meyer et al., 2009a; Mizrachi et al., 2010). Given the considerable distance of most target ornamental taxa to fully sequenced models (Fig. 2), the development of sequence resources in the target species is essential. In addition, deeper functional and evolutionary knowledge in proximal model species is important to interpret the functions of genes in ornamental targets, guiding selection of target floral genes and promoters. The large majority of our knowledge of floral biology results from a single annual species, Arabidopsis thaliana (L.) Heynh. A survey of genomic resources shows that, with the exception of wellstudied taxa like Malus, the development of sequence resources for target ornamental genera is severely lacking (Table 1).

\section{Conclusions}

Plants that have been shown to have invasive tendencies are beginning to be regulated and banned from sale; however, many of these species remain economically important to the nursery industry and local communities. For these plants to remain marketable, sterile forms may need to be developed. Of the genera included in Table 1, those with species listed as noxious weeds and/or banned in various states include Acer, Berberis, Buddleja, Euonymus, Lonicera, and Ulmus. Their inclusion on noxious weed lists, or their being prohibited from being produced and/or sold in various states, will significantly impact growers' sales and reduce plant diversity in landscapes. We have included the other genera in Table 1 because they are also receiving significant attention as weedy or potentially invasive from the scientific and conservation communities,

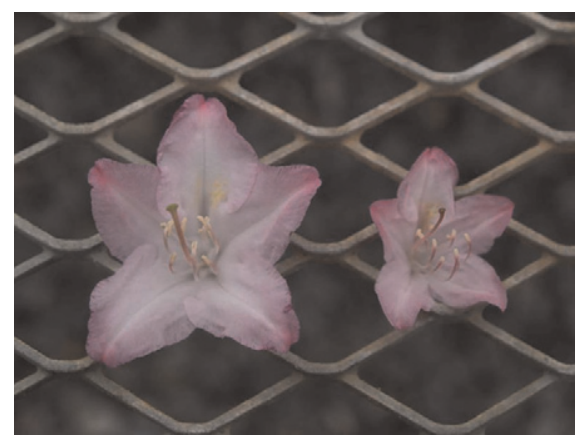

Fig. 3. Flowers from allotetraploid (left) and diploid (right) forms of Rhododendron 'Fragrant Affinity'. Photo: Tom Ranney, North Carolina State University, with permission. and are likely to be listed or banned in many localities the near future. Thus, it would be wise to also develop sterile forms within these genera. As the capacity to produce highly sterile forms through breeding is proven, it is likely that sterile forms of currently banned varieties will be allowed. For example, an amendment to the Oregon noxious weed quarantine (OAR 603-52-1200) provides that cultivars with reduced fertility may be grown and sold.

Techniques such as induced polyploidy, interspecific hybridization, and mutagenesis are relatively inexpensive, do not require highly technical expertise or equipment, and do not face the hurdles of public scrutiny or regulatory agencies that transgenic methods do. The cost of obtaining regulatory approval for transgenic varieties has been estimated to be in the tens of millions of dollars (Miller and Bradford, 2010) and is especially high where there are environmental issues, as there would be for all invasive woody ornamentals. Low cost is important given the fragmentation of the ornamentals industry, where there are very large numbers of varieties and many small producers. Thus, the high research and regulatory costs of transgenic methods are a very substantial obstacle to their application.

Polyploidy, in addition to potentially resulting in a sterile form, often has positive side effects with respect to ornamental qualities such as larger flower size (Fig. 3) or increased heterosis. However, it also has the potential to substantially change variety qualities, a concern where maintenance of the qualities of a highly prized variety is desired. Transgenic methods, which are asexual by definition, are expected to have a much smaller impact on varietal qualities. Both transgenic and conventional methods appear capable of producing highly stable, long-term sterility as has been seen in triploid bananas and seedless grapes, and in ablation-derived male-sterile trees (Strauss et al., 2011). RNAi methods also appear to be highly stable in transgenic trees (Li et al., 2008, 2009b).

Genomic and other sequence information, although very limited at present, are not significant barriers to progress given the rapid development of technology in this area. However, the very primitive state of in vitro biology, and the associated limited ability to produce transgenic plants, is clearly a major obstacle to development of transgenic approaches. Because advanced regeneration systems are generally not needed for conventional in vitro approaches such as ploidy changes and mutagenesis, this pathway seems much more tractable for the majority of genera. Major advances in transgenic methods are required and as discussed previously could be propelled by advances in the use of transformation- and regeneration-promoting genes. The supporting areas of developmental biology have advanced rapidly in recent years, providing many new options for application. However, there has been an extremely small investment in transgenic methods-largely a result of unfavorable economic, regulatory, and market conditions. Barring a major technical breakthrough, these hurdles are likely to remain in place for many years to come.

\section{Literature Cited}

Ackerman, W. and H. Dermen. 1972. A fertile colchiploid from a sterile interspecific camellia hybrid. J. Hered. 63:55-59.

An, X.M., D.M. Wang, Z.L. Wang, B. Li, W.H. Bo, G.L. Cao, and Z.Y. Zhang. 2010. Isolation of a $L E A F Y$ homolog from Populus tomentosa: Expression of PtLFY in P. tomentosa floral buds and PtLFY-IR-mediated gene silencing in tobacco (Nicotiana tabacum). Plant Cell Rpt. 30:89-100.

Arias, R.S., S.A. Filichkin, and S.H. Strauss. 2006 Divide and conquer: Development and cell cycle genes in plant transformation. Trends Biotechnol. 24:267-273.

Bhatti, S. and G. Jha. 2010. Current trends and future prospects of biotechnological interventions through tissue culture in apple. Plant Cell Rpt. 29:1215-1225.

Blakeslee, A.F. and A.G. Avery. 1937. Methods of inducing doubling of chromosomes in plants. J. Hered. 28:393-411.

Bogdanove, A.J. and D.F. Voytas. 2011. TAL effectors: Customizable proteins for DNA targeting. Science 333:1843-1846.

Brunner, A.M., J. Li, S.P. DiFazio, O. Shevchenko, B.E. Montgomery, R. Mohamed, H. Wei, C. Ma, A.A. Elias, K. VanWormer, and S.H. Strauss. 2007. Genetic containment of forest plantations. Tree Genet. Genomes 3:75-100.

Brunner, A.M., R. Mohamed, R. Meilan, L.A. Sheppard, W.H. Rottmann, and S.H. Strauss. 1998. Genetic engineering of sexual sterility in shade trees. J. Arboriculture 24:263-273.

Brunner, A.M. and O. Nilsson. 2004. Revisiting tree maturation and floral initiation in the poplar functional genomics era. New Phytol. 164:43-51.

Chuck, G.S., C. Tobias, L. Sun, F. Kraemer, C. Li, D. Dibble, R. Arora, J.N. Bragg, J.P. Vogel, S. Singh, B.A. Simmons, M. Pauly, and S. Hake. 2011. Overexpression of the maize corngrass 1 microRNA prevents flowering, improves digestibility, and increases starch content of switchgrass. Proc. Natl. Acad. Sci. USA 108: 17550-17555.

Clinton, W.J. 1999. Presidential Executive Order 13112. Federal Register, Doc. 99-3184 64. p. 6183-6186.

Contreras, R.N., T.G. Ranney, and S.P. Tallury. 2007. Reproductive behavior of diploid and allotetraploid Rhododendron L. 'Fragrant Affinity'. HortScience 42:31-34.

Contreras, R.N., J.M. Ruter, and W.W. Hanna. 2009. An oryzalin-induced autoallooctoploid of Hibiscus acetosella 'Panama Red'. J. Amer. Soc. Hort. Sci. 134:553-559.

Contreras, R.N., J.M. Ruter, and B.M. Schwartz. 2010. Oryzalin-induced tetraploidy in Cryptomeria japonica (Cupressaceae). HortScience 45:316-319

Curtin, S.J., F. Zhang, J.D. Sander, W.J. Haun, C Starker, N.J. Baltes, D. Reyon, E.J. Dahlborg, M.J. Goodwin, A.P. Coffman, D. Dobbs, J.K. Joung, D.F. Voytas, and R.M. Stupar. 2011. Targeted mutagenesis of duplicated genes in soybean with zinc-finger nucleases. Plant Physiol. $156: 466-473$.

Dehnen-Schmutz, K. 2011. Determining noninvasiveness in ornamental plants to build green lists. J. Appl. Ecol. 48:1374-1380.

Dunn, B.L. and J.T. Lindstrom. 2007. Oryzalininduced chromosome doubling in Buddleja to 
facilitate interspecific hybridization. HortScience 42:1326-1328.

Egolf, D.R. 1970. Hibiscus syriacus 'Diana', a new cultivar [Malvaceae]. Baileya 17:75-78.

Egolf, D.R. 1981. 'Helene' rose of sharon (althea). HortScience 16:226-227.

Egolf, D.R. 1986. 'Minerva' rose of sharon (althea). HortScience 21:1463-1464.

Egolf, D.R. 1988. 'Aphrodite' rose of sharon (althea). HortScience 23:223-224.

Ellstrand, N.C. and K.A. Schierenbeck. 2000. Hybridization as a stimulus for the evolution of invasiveness in plants? Proc. Natl. Acad. Sci. USA 97:7043-7050.

Flachowsky, H., C. Hättasch, M. Höfer, A. Peil, and M.-V. Hanke. 2009. Overexpression of $L E A F Y$ in apple leads to a columnar phenotype with shorter internodes. Planta 231:251263.

Gartland, J.S., A.T. McHugh, C.M. Brasier, R.J. Irvine, T.M. Fenning, and K.M. Gartland. 2000. Regeneration of phenotypically normal English elm (Ulmus procera) plantlets following transformation with an Agrobacterium tumefaciens binary vector. Tree Physiol. 20: 901-907.

Gelvin, S.B. 2003. Improving plant genetic engineering by manipulating the host. Trends Biotechnol. 21:95-98.

Goldman, M.H., R.B. Goldberg, and C. Mariani. 1994. Female sterile tobacco plants are produced by stigma-specific cell ablation. EMBO J. 13:2976.

Gordon, D.R. 1998. Effects of invasive, nonindigenous plant species on ecosystem processes: Lessons from Florida. Ecol. Appl. 8:975-989.

Gulsen, O., A. Uzun, H. Pala, E. Canihos, and G. Kafa. 2007. Development of seedless and Mal Secco tolerant mutant lemons through budwood irradiation. Sci. Hort. 112:184-190.

Hiratsu, K., K. Matsui, T. Koyama, and M. OhmeTakagi. 2003. Dominant repression of target genes by chimeric repressors that include the EAR motif, a repression domain, in Arabidopsis. Plant J. 34:733-739.

Jones, J.R., T.G. Ranney, and T.A. Eaker. 2008. A novel method for inducing polyploidy in Rhododendron seedlings. J. Amer. Rhododendron Soc. 62:130-135.

Kadota, M. and Y. Niimi. 2002. In vitro induction of tetraploid plants from a diploid Japanese pear cultivar (Pyrus pyrifolia N. cv. Hosui). Plant Cell Rpt. 21:282-286.

Kehr, A.E. 1996. Polyploids in rhododendron breeding. J. Amer. Rhododendron Soc. 50:215-217.

Kermani, M.J., V. Sarasan, A.V. Roberts, K. Yokoya, J. Wentworth, and V.K. Sieber. 2003. Oryzalininduced chromosome doubling in Rosa and its effect on plant morphology and pollen viability. Theor. Appl. Genet. 107:1195-1200.

Lapins, K.O. 1975. Polyploidy and mutations induced in apricot by colchicine treatmeant. Can. J. Genet. Cytol. 17:591-599.

Lapins, K.O. 1983. Mutation breeding, p. 74-99. In: Moore, J.N. and J. Janick (eds.). Methods in fruit breeding. Purdue Univ. Press, West Lafayette, IN.

Lehrer, J.M., M.H. Brand, and J.D. Lubell. 2008. Induction of tetraploidy in meristematically active seeds of Japanese barberry (Berberis thunbergii var. atropurpurea) through exposure to colchicine and oryzalin. Sci. Hort. 119:67-71.

Lermontova, I., O. Koroleva, T. Rutten, J. Fuchs, V. Schubert, I. Moraes, D. Koszegi, and I. Schubert. 2011. Knockdown of CENH3 in Arabidopsis reduces mitotic divisions and causes sterility by disturbed meiotic chromosome segregation. Plant J. 68:40-50.

Li, J., A.M. Brunner, O. Shevchenko, R. Meilan, C. Ma, J.S. Skinner, and S.H. Strauss. 2008 Efficient and stable transgene suppression via RNAi in field-grown poplars. Transgenic Res. 17:679-694.

Li, J., A.M. Brunner, R. Meilan, and S.H. Strauss. 2009 b. Stability of transgenes in trees: Expression of two reporter genes in poplar over three field seasons. Tree Physiol. 29:299-312.

Li, W., D.K. Biswas, H. Xu, C. Xu, X. Wang, J. Liu, and G. Jiang. 2009a. Photosynthetic responses to chromosome doubling in relation to leaf anatomy in Lonicera japonica subjected to water stress. Funct. Plant Biol. 36:783-792.

Li, Y., Z. Cheng, W. Smith, D. Ellis, Y. Chen, X. Zheng, Y. Pei, K. Luo, D. Zhao, Q. Yao, H. Duan, and Q. Li. 2004. Invasive ornamental plants: Problems, challenges, and molecular tools to neutralize their invasiveness. Crit. Rev. Plant Sci. 23:381-389.

Liu, Z. and D. Li. 2011. Epigenetic silencing of floral genes, p. 69-70. In: The science of gene flow in agriculture and its role in co-existence. University of California at Davis, Department of Plant Sciences, Washington, DC.

Mariani, C., M.D. Beuckeleer, J. Truettner, J. Leemans, and R.B. Goldberg. 1990. Induction of male sterility in plants by a chimaeric ribonuclease gene. Nature 347:737-741.

Martinez, D.A. and M.A. Nelson. 2010. The next generation becomes the now generation. PLoS Genet. 6:e1000906.

Meyer, E., G.V. Aglyamova, S. Wang, J. BuchananCarter, D. Abrego, J.K. Colbourne, B.L. Willis, and M.V. Matz. 2009a. Sequencing and de novo analysis of a coral larval transcriptome using 454 GSFlx. BMC Genomics 10:219.

Meyer, E.M., D.H. Touchell, and T.G. Ranney. 2009 b. In vitro shoot regeneration and polyploid induction from leaves of Hypericum species. HortScience 44:1957-1961.

Michaels, S.D. and R.M. Amasino. 1999. FLOWERING LOCUS C encodes a novel MADS domain protein that acts as a repressor of flowering. Plant Cell 11:949-956.

Miller, J.K. and K.J. Bradford. 2010. The regulatory bottleneck for biotech specialty crops. Nat. Biotechnol. 28:1012-1014.

Miyashita, T., T. Ohashi, F. Shibata, H. Araki, and Y. Hoshino. 2009. Plant regeneration with maintenance of the endosperm ploidy level by endosperm culture in Lonicera caerulea var. emphyllocalyx. Plant Cell Tissue Organ Cult. 98:291-301.

Mizrachi, E., C.A. Hefer, M. Ranik, F. Joubert, and A.A. Myburg. 2010. De novo assembled expressed gene catalog of a fast-growing Eucalyptus tree produced by Illumina mRNA-Seq. BMC Genomics 11:681.

Mohamed, R., C. Wang, C. Ma, O. Shevchenko, S.J. Dye, J.R. Puzey, E. Etherington, X. Sheng, R. Meilan, S.H. Strauss, and A.M. Brunner. 2010. Populus CEN/TFL1 regulates first onset of flowering, axillary meristem identity and dormancy release in Populus. Plant J. 62:674-688.

Moon, H.S., L.L. Abercrombie, S. Eda, R. Blanvillain, J.G. Thomson, D.W. Ow, and C.N. Stewart, Jr. 2011. Transgene excision in pollen using a codon optimized serine resolvase CinH-RS2 site-specific recombination system. Plant Mol. Biol. 75: 621-631.

Newhouse, A.E., F. Schrodt, C.A. Maynard, and W.A. Powell. 2006. American Elm (Ulmus americana). Methods Mol. Biol. 344:99-112.

Olmo, H.P. 1960. Plant breeding program aided by radiation treatment. Calif. Agr. 14:4.
Olsen, R.T., T.G. Ranney, and Z. Viloria. 2006a. Reproductive behavior of induced allotetraploid $\times$ Chitalpa and in vitro embryo culture of polyploid progeny. J. Amer. Soc. Hort. Sci. 131:716-724.

Olsen, R.T., T.G. Ranney, and D.J. Werner. 2006b. Fertility and inheritance of variegated and purple foliage across a polyploid series in Hypericum androsaemum L. J. Amer. Soc. Hort. Sci. 131:725-730.

Pimentel, D., R. Zuniga, and D. Morrison. 2005. Update on the environmental and economic costs associated with alien-invasive species in the United States. Ecol. Econ. 52:273-288.

Pounders, C., T. Rinehart, and H. Sakhanokho. 2007. Evaluation of interspecific hybrids between Lagerstroemia indica and L. speciosa. HortScience 42:1317-1322.

Randolph, L.F. 1941. An evaluation of induced polyploidy as a method of breeding crop plants. Amer. Nat. 75:347-363.

Reichard, S.H. and C.W. Hamilton. 1997. Predicting invasions of woody plants introduced into North America. Conserv. Biol. 11:193-203.

Renfro, S.E., B.M. Burkett, B.L. Dunn, and J.T. Lindstrom. 2007. 'Asian moon' Buddleja. HortScience 42:1486-1487.

Richardson, D.M. and P. Pyšek. 2006. Plant invasions: Merging the concepts of species invasiveness and community invasibility. Prog. Phys. Geogr. 30:409-431.

Rose, J.B., J. Kubba, and K.R. Tobutt. 2000a. Chromosome doubling in sterile Syringa vulgaris $\times S$. pinnatifolia hybrids by in vitro culture of nodal explants. Plant Cell Tissue Organ Cult. 63:127-132.

Rose, J.B., J. Kubba, and K.R. Tobutt. 2000b. Induction of tetraploidy in Buddleia globosa. Plant Cell Tissue Organ Cult. 63:121-125.

Rounsaville, T.J. and T.G. Ranney. 2010. Ploidy levels and genome sizes of Berberis L. and Mahonia Nutt. species, hybrids, and cultivars. HortScience 45:1029-1033.

Schuerman, P.L. and A.M. Dandekar. 1993. Transformation of temperate woody crops: Progress and potentials. Sci. Hort. 55:101-124.

Shendure, J. and H. Ji. 2008. Next-generation DNA sequencing. Nat. Biotechnol. 26:11351145.

Shukla, V.K., Y. Doyon, J.C. Miller, R.C. DeKelver, E.A. Moehle, S.E. Worden, J.C. Mitchell, N.L. Arnold, S. Gopalan, X. Meng, V.M. Choi, J.M. Rock, Y.Y. Wu, G.E. Katibah, G. Zhifang, D. McCaskill, M.A. Simpson, B. Blakeslee, S.A. Greenwalt, and H.J. Butler. 2009. Precise genome modification in the crop species Zea mays using zinc-finger nucleases. Nature 459:437441.

Skinner, J.S., R. Meilan, A.M. Brunner, and S.H. Strauss. 2000. Options for genetic engineering of floral sterility in forest trees, p. 135-153. In: Jain, S.M. and S.C. Minocha (eds.). Molecular Biology of Woody Plants, Kluwer, Netherlands.

Sosinski, B., S. Jung, I. Verde, J. Schmutz, E. Scholl, M. Staton, A.G. Abbott, D. Main, M. Morgante, and D. Rokhsar. 2010. The peach genome sequence and its utility for comparative genomics. Plant \& Animal Genomes XVIII Conference, San Diego, CA.

Stebbins, G.L. 1950. Polyploidy I: Occurrence and nature of polyploid types, p. 298-341. In: Variation and evolution in crop plants. Columbia Univ. Press, New York, NY.

Strauss, S.H., W.H. Rottmann, A.M. Brunner, and L.A. Sheppard. 1995. Genetic engineering of reproductive sterility in forest trees. Mol. Breed. 1:5-26. 
Strauss, S.H., C. Zhang, and M. Hinchee. 2011. Gene flow control in forest trees: Approaches and progress, p. 80-83. In: The science of gene flow in agriculture and its role in co-existence. University of California at Davis, Department of Plant Sciences, Washington, DC.

Sun, Q., H. Sun, L. Li, and R.L. Bell. 2009. In vitro colchicine-induced polyploid plantlet production and regeneration from leaf explants of the diploid pear (Pyrus communis L.) cultivar, 'Fertility'. J. Hort. Sci. Biotechnol. 84:548-552.

Suzuki, T., M. Uenohata, and K. Oosawa. 2006. Polyploidy breeding of blue honeysuckle and black chokeberry by utilizing in vitro-cultures treated with colchicine. Acta Hort. 760:389396.

Szankowski, I., C. Hattasch, M.V. Hanke, H. Flachowsky, S. Waidmann, and A. El-Din Saad Omar. 2009. RNAi-silencing of MdTFL1 induces early flowering in apple. Acta Hort. 839:633-636.

Thammina, C., M. He, L. Lu, K. Cao, H. Yu, Y. Chen, L. Tian, J. Chen, R. McAvoy, D. Ellis, D. Zhao, Y. Wang, X. Zhang, and Y. Li. 2011. In vitro regeneration of triploid plants of Euonymus alatus 'Compactus' (burning bush) from endosperm tissues. HortScience 46:1141-1147.

The Arabidopsis Genome Initiative. 2000. Analysis of the genome sequence of the flowering plant Arabidopsis thaliana. Nature 408:796815.

Tränkner, C., S. Lehmann, H. Hoenicka, M.-V. Hanke, M. Fladung, D. Lenhardt, F. Dunemann, A. Gau, K. Schlangen, M. Malnoy, and H.
Flachowsky. 2010. Over-expression of an FT-homologous gene of apple induces early flowering in annual and perennial plants. Planta 232:1309-1324.

Trueblood, C.E., T.G. Ranney, N.P. Lynch, J.C. Neal, and R.T. Olsen. 2010. Evaluating fertility of triploid clones of Hypericum androsaemum L. for use as non-invasive landscape plants. HortScience 45:1026-1028.

Tuskan, G.A., S. DiFazio, S. Jansson, J. Bohlmann, and I. Grigoriev, et al. 2006. The genome of black cottonwood, Populus trichocarpa (Torr. \& Gray). Science 313:1596-1604.

United States Department of Agriculture. 2012. Invasive and noxious weeds. 18 June 2012 $<$ http://plants.usda.gov/java/noxiousDriver $>$.

University of Georgia. 2012. Invasive plant atlas of the United States. 18 June 2012. <http:// www.invasiveplantatlas.org/distribution.html $>$.

Van Laere, K., L. Leus, J. Van Huylenbroeck, and E. Van Bockstaele. 2009. Interspecific hybridisation and genome size analysis in Buddleja. Euphytica 166:445-456.

Velasco, R., A. Zharkikh, J. Affourtit, A. Dhingra, and A. Cestaro, et al. 2010. The genome of the domesticated apple (Malus $\times$ domestica Borkh.). Nat. Genet. 42:833-839.

Viswanath, V., and S.H. Strauss. 2010. Modifying plant growth the cisgenic way. Info. Sys. Biotechnol. News Rpt. Sept. 2010. p. 1-4.

Wang, Y., Y.Y. Yau, D. Perkins-Balding, and J.G. Thomson. 2011a. Recombinase technology: Applications and possibilities. Plant Cell Rpt. 30:267-285.
Wang, J.-W., M.Y. Park, L.-J. Wang, Y. Koo, X.-Y. Chen, D. Weigel, and R.S. Poethig. 2011b. MiRNA control of vegetative phase change in trees. PLoS Genet. 7:e1002012.

Werner, D.J. and L.K. Snelling. 2009. 'Blue Chip' and 'Miss Ruby' Buddleja. HortScience 44: 841-842.

Williamson, M. and A. Fitter. 1996. The varying success of invaders. Ecol. 77:1661-1666.

Yamagishi, N., S. Sasaki, K. Yamagata, S. Komori, M. Nagase, M. Wada, T. Yamamoto, and N. Yoshikawa. 2010. Promotion of flowering and reduction of a generation time in apple seedlings by ectopical expression of the Arabidopsis thaliana FT gene using the Apple latent spherical virus vector. Plant Mol. Biol. 75:193204.

Zadoo, S.N., R.P. Roy, and T.N. Khoshoo. 1975. Cytogenetics of cultivated bougainvilleas. $\mathrm{V}$. Induced tetraploidy and restoration of fertility in sterile cultivars. Euphytica 24:517-524.

Zhang, C., K.H. Norris-Caneda, W.H. Rottmann, J.E. Gulledge, S. Chang, B.Y.-H. Kwan, A.M. Thomas, L.C. Mandel, R.T. Kothera, A.D. Victor, L. Pearson, and M.A.W. Hinchee. 2012. Control of pollen mediated gene flow in transgenic trees. Plant Physiol. 159:1319-1334.

Zhang, F. and D.F. Voytas. 2011. Targeted mutagenesis in Arabidopsis using zinc-finger nucleases. Methods Mol. Biol. 701:167-177.

Zhu, L.H., X.Y. Li, and M. Welander. 2007. Overexpression of the Arabidopsis gai gene in apple significantly reduces plant size. Plant Cell Rpt. 27:289-296. 